\title{
A study of "The Portrait of F.P. Makerovsky in a Masquerade Costume" by Dmitry Levitsky from the collection of the State Tretyakov Gallery
}

\author{
Nikolay P. Simonenko ${ }^{1,2^{*}}$ (D, Valentin R. Solovey ${ }^{1}$, Kirill V. Shumikhin ${ }^{3}$, Anna A. Lizunova ${ }^{1}$, Stepan V. Lisovskii ${ }^{1}$, \\ Elena A. Liubavskaya33, Tatyana V. Seregina ${ }^{3}$, Irina G. Basova³, Yulia B. Dyakonova ${ }^{3}$, Tatiana L. Simonenko², \\ Elizaveta P. Simonenko², Ivan A. Volkov' ${ }^{1}$, Yulian A. Khalturin ${ }^{3}$ and Viktor V. Ivanov ${ }^{1}$
}

\begin{abstract}
This paper reports on activities carried out as part of a pre-conservation studies of the painting by Dmitry Levitsky, "The Portrait of F.P. Makerovsky in a Masquerade Costume" (1789, the State Tretyakov Gallery). Samples were taken and prepared for further study within the following algorithm. Using optical microscopy of cross-sections of the samples taken, structural elements of layered compositions were revealed and external differences between them were established. X-ray fluorescence spectroscopy was used to evaluate the elemental composition of the painting surface and cross-sections of samples. Scanning electron microscopy combined with energy dispersive X-ray spectroscopy was used to clarify the elemental composition of each of the structural elements of the samples taken, their submicro- and microdimensional inclusions, to map the distribution of chemical elements over the studied surface, and to determine the dispersion of organic and inorganic components contained in the material. Micro-FTIR was used to identify functional groups and to determine the main classes of inorganic compounds, as well as binders, used, including in the local analysis of micro-inclusions. The list of specific chemical compounds in the composition of the studied paint layers and grounds, which included an examination of the varnish coating, was determined with microRaman spectroscopy using data obtained by the above methods. As a result of the study, complementary information was obtained on the chemical composition of the inorganic components used, of the binder and of the varnish coating, which is required for further conservation of this work of art.
\end{abstract}

Keywords: Multi-analytical studies, Micro-analysis, Material identification, Conservation, Painting, Pigment, Binder, Levitsky, Makerovsky

\section{Introduction}

The studied painting is the work of one of the most famous Russian masters of the eighteenth century, Dmitry Levitsky (1735-1822), whose name can be justly

\footnotetext{
*Correspondence: n_simonenko@mail.ru

${ }^{1}$ Moscow Institute of Physics and Technology, Institutskiy per. 9, Moscow Region, Dolgoprudny 141701, Russia

Full list of author information is available at the end of the article
}

brought into line with the most gifted portrait painters of his era.

Levitsky's skill was greatly appreciated by contemporaries; moreover, for 17 years, he headed the portrait class of the Academy of Arts in St. Petersburg. He succeeded in both ceremonial portraits of court aristocrats and intimate portraits of his peers. One aspect of Levitsky's diverse heritage is children's portraits, in which the master also seeks to emphasise the individuality of the model.
Springer Open

(c) The Author(s) 2020. This article is licensed under a Creative Commons Attribution 4.0 International License, which permits use, sharing adaptation, distribution and reproduction in any medium or format, as long as you give appropriate credit to the original author(s) and the source, provide a link to the Creative Commons licence, and indicate if changes were made. The images or other third party material in this article are included in the article's Creative Commons licence, unless indicated otherwise in a credit line to the material. If material is not included in the article's Creative Commons licence and your intended use is not permitted by statutory regulation or exceeds the permitted use, you will need to obtain permission directly from the copyright holder. To view a copy of this licence, visit http://creativeco mmons.org/licenses/by/4.0/. The Creative Commons Public Domain Dedication waiver (http://creativecommons.org/publicdomain/ zero/1.0/ applies to the data made available in this article, unless otherwise stated in a credit line to the data. 
The portrait of Favst Petrovich Makerovsky (17801847) remained in a family collection for a long time. The grandson of the young man represented in the portrait, D.F. Makerovsky, rejected all offers to sell the heirloom. Only after his death in 1913 it became possible to purchase the painting from the heir, N.S. Gavrilov. After examination of the painting by the Gallery conservators, it was discovered that the canvas consisted of three pieces, sewn horizontally. On the upper part, about $92 \mathrm{~cm}$ high, a figure is painted, approximately to the knees. The two lower parts of the canvas had a height of about 14 and $8 \mathrm{~cm}$, respectively. Moreover, it was found that painting condition was unsatisfactory $-80 \%$ of the painting surface was overpainted and covered with a thick layer of dark varnish, there were numerous breaks in the ground, tears and shrinkage within the paint layer, craquelures, especially in the two lower parts. In addition, the red cloak had specific damage, which often occurs under the impact of high temperature.

In 1914, the Gallery turned for help to the Moscow practising conservator Ivan Kraytor (1880-1957). The Tretyakov Gallery archive contains a portrait conservation dossier [1], and later Kraytor published a brochure about this, where valuable information about the work can still be found.

Kraytor performed a series of experiments, as a result of which it was decided that the painting was damaged due to the presence of asphalt in the varnish. Based on a technological studies at the beginning of the twentieth century, it was also suggested that, in the nineteenth century, the portrait had undergone conservation using "one of those yellow paints that conservators of the nineteenth century used to give the paintings the so-called 'gallery tone"'.

Kraytor only managed to eliminate the contaminants from the painting surface, and regenerate the varnish using the method of Professor Pettenkofer. The varnish and overpaint were removed by another famous conservator of the beginning of the twentieth century, Dmitry Bogoslovskiy (1870-1939), who, unfortunately, left no descriptions. Since then, the portrait has not been restored.

During the inspection of the painting in 2017, it was decided that there was a need for a complex restoration of the painting. The artist's canvas became brittle and lost elasticity, and the canvas edges were partially lost and torn. The craquelure pattern on two sewn parts has hard, raised edges with a threat of detachment. In red areas there is a marked shrinking of the paint layer. A thick layer of yellowed varnish distorts the artist's palette. It feels like the entire top of the landscape is under a layer of overpaint. Experts were faced with tasks left unfinished from the beginning of the twentieth century: to clear the portrait of later overpaint and yellowed varnish, and to strengthen the paint layer. In addition, it is planned to reline the canvas.

In the past, experts have approached to study Levitsky's technique. However it is very important to note that earlier conclusions about art materials were often made based on visual analysis, observational experience, a limited set of study methods and practical work in the field of conservation.

In this regard, before conservation, it was decided to conduct a number of physico-chemical studies of "The Portrait of F.P. Makerovsky" to meet the following objectives: to determine the set of artistic materials used by the artist in the portrait, and to compare these materials on the three parts of the canvas, namely the main part of the canvas, which is undoubtedly the one originally used by the artist, and the two smaller extension pieces, whose origin and date of occurrence should also be considered.

\section{Experimental}

To pursue these objectives, it is necessary to use a range of physicochemical analysis methods. First of all noninvasive study methods were used-optical microscopy and X-ray fluorescence spectroscopy (XRF). Optical microscopy enables an analysis of the artist's pictorial style, and makes it possible to draw conclusions about the state of preservation of the work, and reveal the fundamental structural elements of the composition. $\mathrm{X}$-ray fluorescence spectroscopy can provide information on the inorganic pigments used by the artist [2]. In the next step, the need for sampling was identified. It was necessary to estimate the stratigraphy of various sections of the painting with the use of optical microscopy and more accurately study the composition of individual layers by elemental analysis. In discussion with the conservator and the curator, the most appropriate sampling sites were selected, and then samples were taken to produce cross-sections. Technovit 2200 LC light-curing resin was used as a medium for production of cross-sections. Further work was carried out directly on cross-sections. To refine the elemental composition of each of the structural elements of the samples, in order to construct maps of the distribution of chemical elements over the studied surface and to determine their dispersion, the method of scanning electron microscopy (SEM) combined with energy dispersive X-ray spectroscopy (EDX) was used [3-5]. Next, in order to establish the classes of inorganic components, the samples were studied using the spectral analysis methods IR Fourier spectroscopy and Raman spectroscopy. The method of micro-Fourier transform infrared spectroscopy (micro-FTIR) made it possible to identify the functional groups and main classes of 
inorganic compounds and binding media [6-9]. MicroRaman spectroscopy (micro-RS) made it possible to then establish a list of the specific chemical compounds contained in various structural elements of the samples [10-13]. This approach enabled identification of the organic binders contained in the sample and an evaluation of the degree of their polymerization, which is related to their age or level of ageing $[14,15]$.

The sequence of work and methods described enabled a more complete picture of the materials used by the author, and their current state, to be developed. This, in turn, made progress in answering the questions posed at the beginning of the study.

\section{Sampling procedure}

To study Levitsky's painting, “The Portrait of F.P. Makerovsky in a Masquerade Costume", samples of structural paint compositions were taken from different parts of the canvas. Thus, one sample (sample 1) was taken from the main canvas, two samples (samples 2 and 4 ) from the first extension piece, and one sample (sample 3 ) from the second extension piece. To study the composition of the varnish layer, varnish micro-flakes were also taken from the painting surface (samples 5 and 6) (Fig. 1, red markers).

Samples were taken with a scalpel under a microscope, in the presence of a conservator and curator of the studied work. Subsequently, cross-sections were made of them with the use of Technovit 2000 photocurable resin in accordance with the sample preparation scheme (Fig. 2).

Using a Lomo BIOLAM M-1 optical microscope equipped with a Levenhuk M1400 PLUS high-resolution digital camera, the quality of the surface formed was monitored in the dark-field mode using an additional light source, followed by high-resolution photography of the sample. When grinding and polishing the sample, the morphological, chemical and mechanical properties of the materials were taken into account in order to avoid destruction of the sample and mixing of polymer with sample layers. Varnish micro-flakes for further analysis were transferred to $\mathrm{KBr}$ glasses using a scalpel for further analysis.

X-ray fluorescence spectroscopy was used to perform the initial elemental analysis of the surface of the studied painting at 20 points (Fig. 1, white markers), and cross-sections of the samples taken. At points 18 and 19, located on the right edge of the canvas, the ground was examined, due to the absence of paint layers. The measurements were made using an Artax (Bruker) spectrometer with the following parameters: signal accumulation time-20 s, voltage $-50 \mathrm{kV}$, atmosphere-air, molybdenum anode, optics-collimator 0.200 .
Microscopic studies were carried out using scanning electron microscopes Jeol JSM 7001F and Carl Zeiss NVision 40, with an attachment for energy dispersive elemental microanalysis Oxford Instruments X-Max. Images of the section surface were obtained at a low accelerating voltage $(1 \mathrm{kV})$ using secondary electron detectors to visualise the surface relief and reflected electrons (contrast mode by the average atomic number) to produce images of inorganic inclusions in the binder matrix, as well as to conduct qualitative elemental analysis of the studied surface. To conduct energy dispersive analysis with the aim of generating maps of the distribution of elements on the section surface of the studied samples, and of determining the chemical composition of the paint layers and ground, a tungsten film about $10 \mathrm{~nm}$ thick was initially deposited onto the section surface, to encourage charge draining.

Several layers of paint coatings and grounds, in the form of cross-sections, as well as the surface of varnish flakes, were studied using the micro-FTIR method using a Lumos (Bruker) spectrometer. The spectra were obtained in attenuated total reflection (ATR) mode with a $\mathrm{ZnSe}$ element. The spectra were obtained with the following parameters: resolution $-2 \mathrm{~cm}^{-1}, 250$ scans, total spectrum accumulation time- 3 min.

Raman spectra were recorded using a semi-automatic system DXR Raman Microscope (Thermo Fisher Scientific Inc.) consisting of a spectrometer equipped with a laser with a wavelength of $780 \mathrm{~nm}$ and a characteristic focal spot size of $1.2-1.9 \mu \mathrm{m}$. The signal was recorded in the wavenumber range of $100-3400 \mathrm{~cm}^{-1}$. When studying the layers of cross-sections of the studied samples and the surface of the varnish flakes, laser beam positioning was carried out using the built-in confocal microscope (at magnifications of $10 \times$ and $20 \times$, depending on the thickness of the layer or the size of inclusions). The laser output power $(2-24 \mathrm{~mW})$, the signal accumulation time (3-40 s) and the number of scans (5-500) varied depending on the spectral properties of the studied material. Data were processed using OMNIC for Dispersive Raman 9.5.9 software (Thermo Fisher Scientific Inc.).

\section{Results and discussion}

\section{Historical studies}

The study of historical materials shows that there were earlier attempts to understand features of Levitsky's technique. The first one dates back to the early 1920 s. Then, on a larger scale, Alexey Rybnikov, a curator and conservator of the Tretyakov Gallery, dealt with this problem. In his book "The Texture of Classical Paintings" [16], he pays great attention to studying the causes of craquelure and shrinkage, suggesting that the artist uses excessive oil in the lower layers of the painting. "The painted surface, 
which is losing its appearance in the abundance of oil, usually suffers from this excess of liquid, which, while shrinking, distorts the entire texture of works". Later, all researchers of Levitsky described the same feature of the artist that appeared in the 1780-1790s, his "liquid" brushwork and how this affected the preservation of the works later. All damage in the portrait of Makerovsky is the result of the use of "excess or bad quality oil" [17].

Researchers have paid much attention to the composition of the artist's grounds. In the eighteenth century painters mostly used coloured, multilayer grounds.
Levitsky used mainly light ochre ground, but there were also light grey and light brown grounds. Alla Luzhetskaya, a famous researcher of the artist's oeuvre, noted that "for Levitsky, the ground colour is the starting point for building the colour scheme of his paintings, and he varies it depending on the paint composition of his works" [17]. It has been repeatedly noted that the artist's grounds consisted of two layers, sometimes even three. Ground fillers were white lead, chalk and ochre in various proportions. In some works the presence of charcoal was observed. "An important technological feature is that

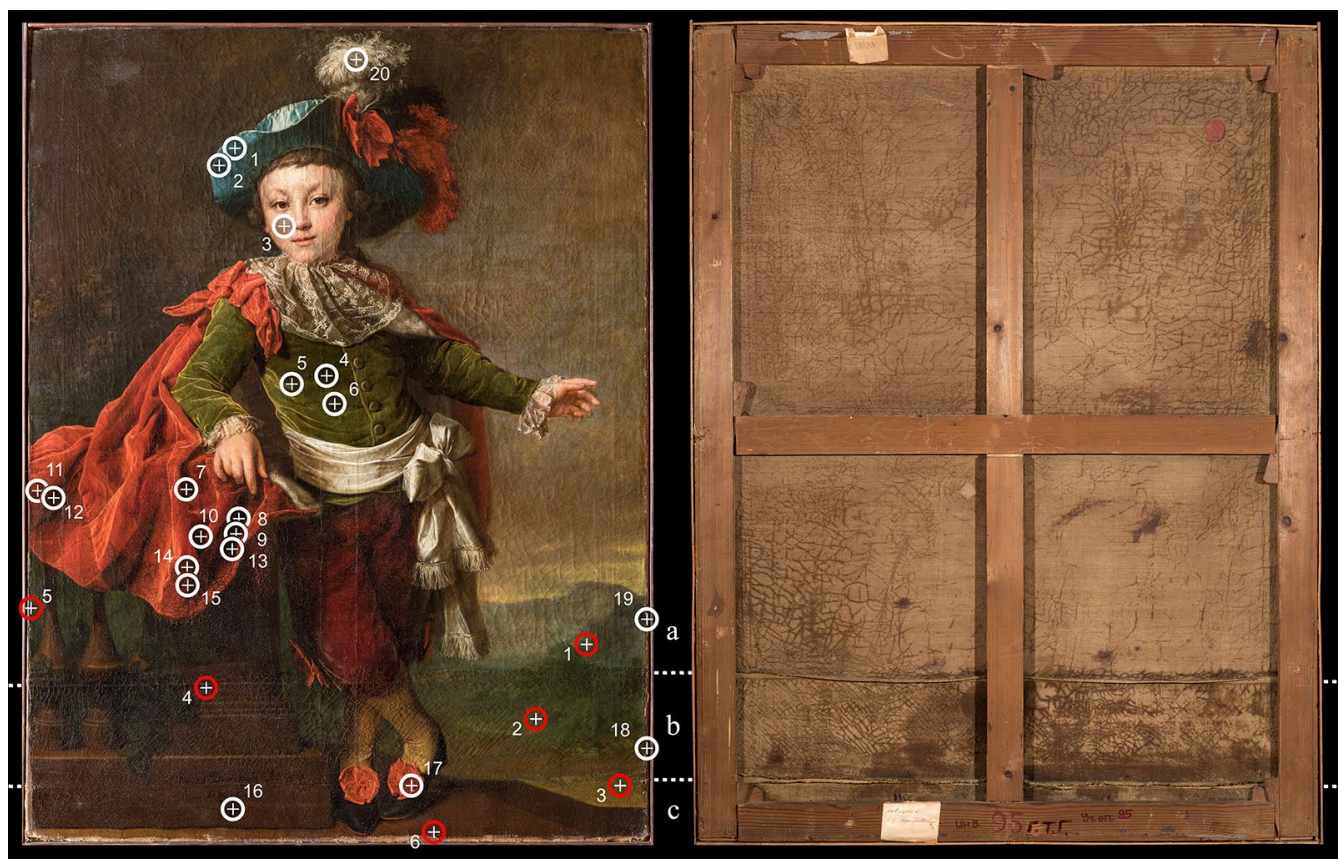

Fig. 1 Sampling pattern (red markers) and surface points examined by XRF (left); canvas rear (right); $a$ the main part of the canvas, $b$ the first extension piece, $c$ the second extension piece

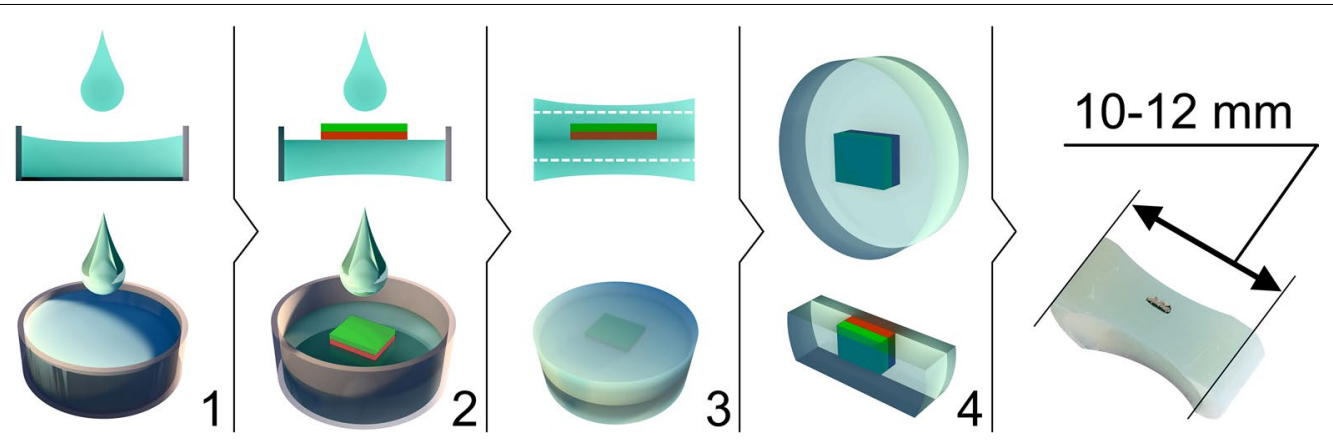

Fig. 2 Sample preparation pattern and the appearance of a typical cross-section of a sample fixed in a photo-polymer 


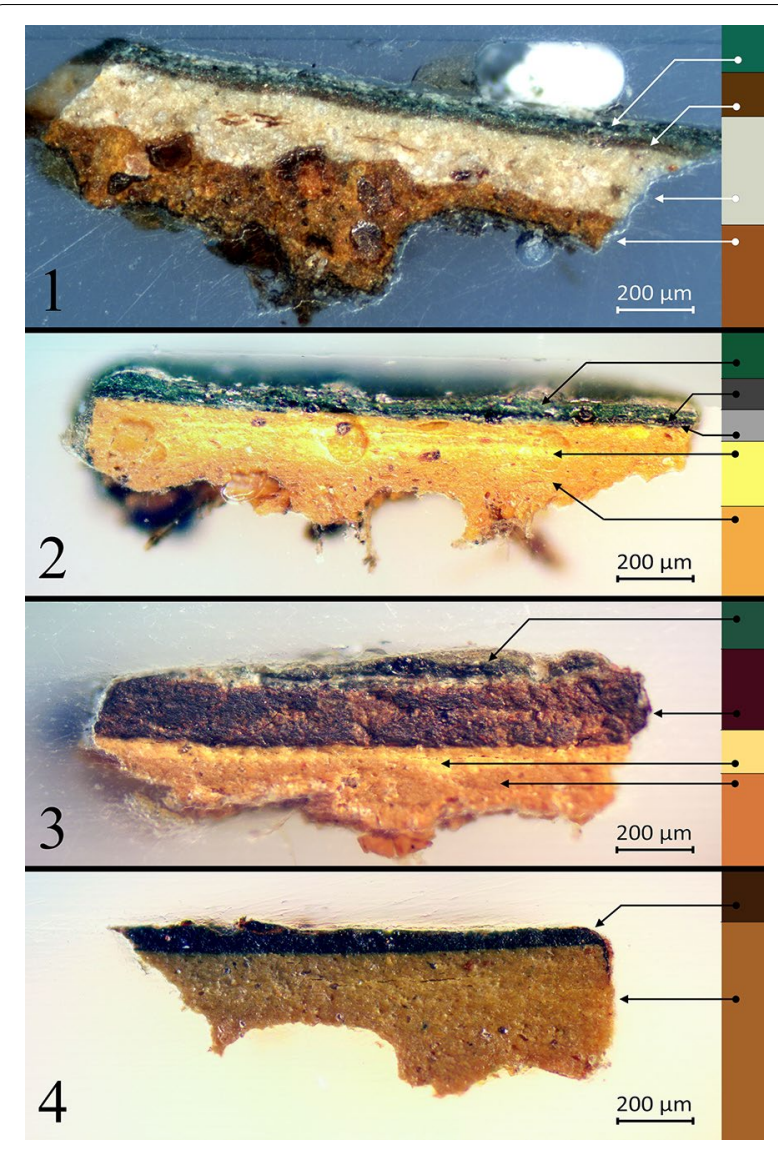

Fig. 3 Optical micrographs of cross-sections of samples 1-4

the chalk was combined in grounds not only with ochre but also with white lead in small quantities in the upper layers" [18]. More modern studies show that sometimes Prussian blue was found in grounds, and in one case vermillion was found.

As for the artist's palette, Alla Luzhetskaya suspected the presence of asphalt in some of his paintings, and especially in the portrait of Makerovsky. In the catalogue dedicated to the exhibition to the 250th anniversary of Levitsky, in Russian Museum in 1985, Svetlana RimskayaKorsakova described the results of a technological studies that delved into the artist's technique. She found, in some works in dark glaze, "a mixture of umber with coarsegrained mineral particles, among which large grains of blue and green malachite stand out" [19].

\section{Optical microscopy}

Using optical microscopy of cross-sections of samples 1-4 (Fig. 3), a list of layers was determined in each case. Thus, sample No. 1 had two paint layers, (the upper one was green, the lower one was brown), with a thickness of about $50 \mu \mathrm{m}$ each, and two ground layers, (the upper one was white, the lower one was brown). The two-layer ground structure significantly distinguishes this sample from others. Sample No. 2 was characterised by three thinner paint layers, (the upper one was green, $\sim 40 \mu \mathrm{m}$ thick; the middle one was dark grey, $\sim 20 \mu \mathrm{m}$; the lower one was light grey, $\sim 10 \mu \mathrm{m}$ ), and brown ground with a vague light brown inter-layer in the upper part. When analysing the cross-section of sample No. 3, two paint layers were observed that differed significantly in thickness; (the upper one was green, $\sim 80 \mu \mathrm{m}$; the lower one was brown, $150 \mu \mathrm{m})$. The much larger total thickness of the paint layers, in this case, distinguishes the specified sample from the first two, and the ground colour and structure were similar to sample No. 2. Sample No. 4 consisted of a brown paint layer $(\sim 80 \mu \mathrm{m})$ and a lighter brown ground which had a uniform colour throughout its thickness. Thus, samples 1 and 2 were similar in terms of the structure of the paint layers, samples 2 and 3 had a similar ground structure, sample No. 1, like No. 4, differed from all in ground structure, and sample No. 3 differed from all due to the great thickness of the brown paint layer. In this regard, according to optical microscopy, the studied samples can be divided into three groups by the structure of the paint layers $(1+2,3,4)$ and that of the ground $(1,2+3,4)$.

\section{X-ray fluorescence}

The initial elemental analysis of the painting surface studied at 20 points (Fig. 1, white markers), and of crosssections of samples 1-4 (red markers), was performed using the XRF method. As can be seen from the results of scanning of the painting surface (Table 1), at almost all the studied points (with the exception of Nos. 16 and 17), lead was detected as the main component, probably related to the white lead pigment $\left(\left(\mathrm{PbCO}_{3}\right)_{2} \cdot \mathrm{Pb}(\mathrm{OH})_{2}\right)$ contained in the ground. When analysing areas with a red colour (main canvas, points 7-15), mercury was found in almost every case, which is included as a compound of the red vermillion pigment ( $\mathrm{HgS})$. In the case of point 17 (the second extension piece), located in a different part of the painting, mercury was the main element found, which may indicate the use of different paint compositions in these areas, or the use of various techniques to form paint layers. When conducting analysis at point 16 (the second extension piece), corresponding to the brown area of the paint coating, the main element detected was iron, which was probably included in such brown pigments as ochre $\left(\mathrm{FeO}(\mathrm{OH}) \cdot \mathrm{nH}_{2} \mathrm{O}\right)$ or hematite $\left(\mathrm{Fe}_{2} \mathrm{O}_{3}\right)$. The study of the green area of the painting (points 4-6, the main canvas) showed the presence of copper, which is included in a large number of green pigments: malachite $\left(\mathrm{CuCO}_{3} \cdot \mathrm{Cu}(\mathrm{OH})_{2}\right)$, verdigris $\left(\mathrm{Cu}\left(\mathrm{CH}_{3} \mathrm{COO}\right)_{2} \cdot 2 \mathrm{Cu}(\mathrm{OH})_{2}\right)$, etc. The analysis of the remaining marked points, 


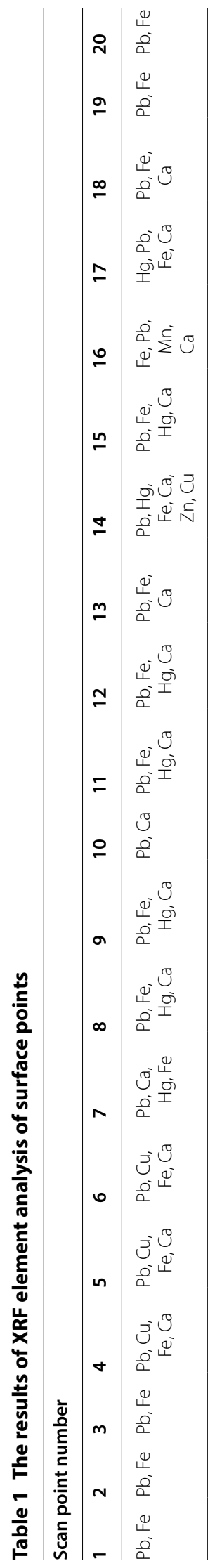


including those in areas where there are no paint layers and only the ground is observed (points 18 and 19), indicated the presence of lead with an impurity of iron. The estimated composition of inorganic pigments is not univocal, but is proposed on the basis of a list of the most common pigments used in the late eighteenth century.

The analysis of cross-sections of samples 1-4 made it possible to evaluate the distribution of main chemical elements by thickness of the corresponding compositions consisting of paint layers and grounds (Table 3). Thus, the area comprising the green and brown paint layers of sample No. 1, contained lead, mercury and iron (in decreasing order of quantity), the light ground contained lead and iron, and the dark ground contained iron, lead, calcium and manganese. The dark shade of the lower ground is probably due to the presence of iron and manganese compounds. The study of the paint layers of sample No. 2 showed the presence of lead and iron, and in the composition of the ground, in addition to the specified elements, titanium was found. Therewith, the composition of the light brown ground inter-layer also included calcium, which is contained in the common white calcite filler $\left(\mathrm{CaCO}_{3}\right)$, which apparently determines its lighter shade. The analysis of the paint layers of sample No. 3 showed the presence of lead, iron, manganese, titanium and calcium. Probably, the compounds of iron
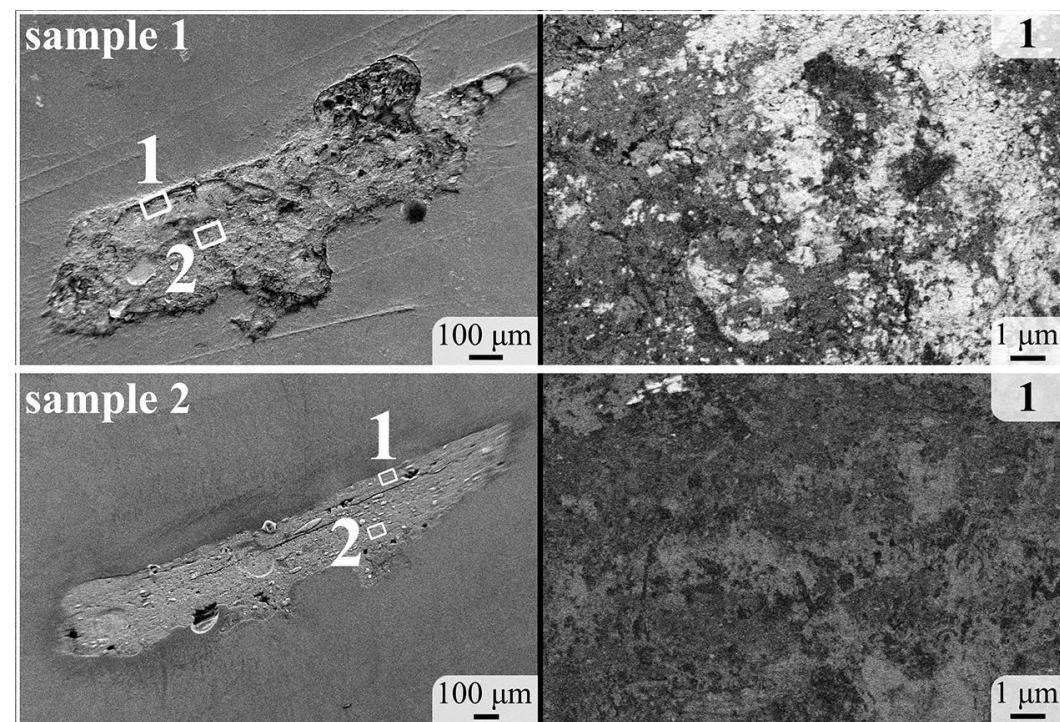

1
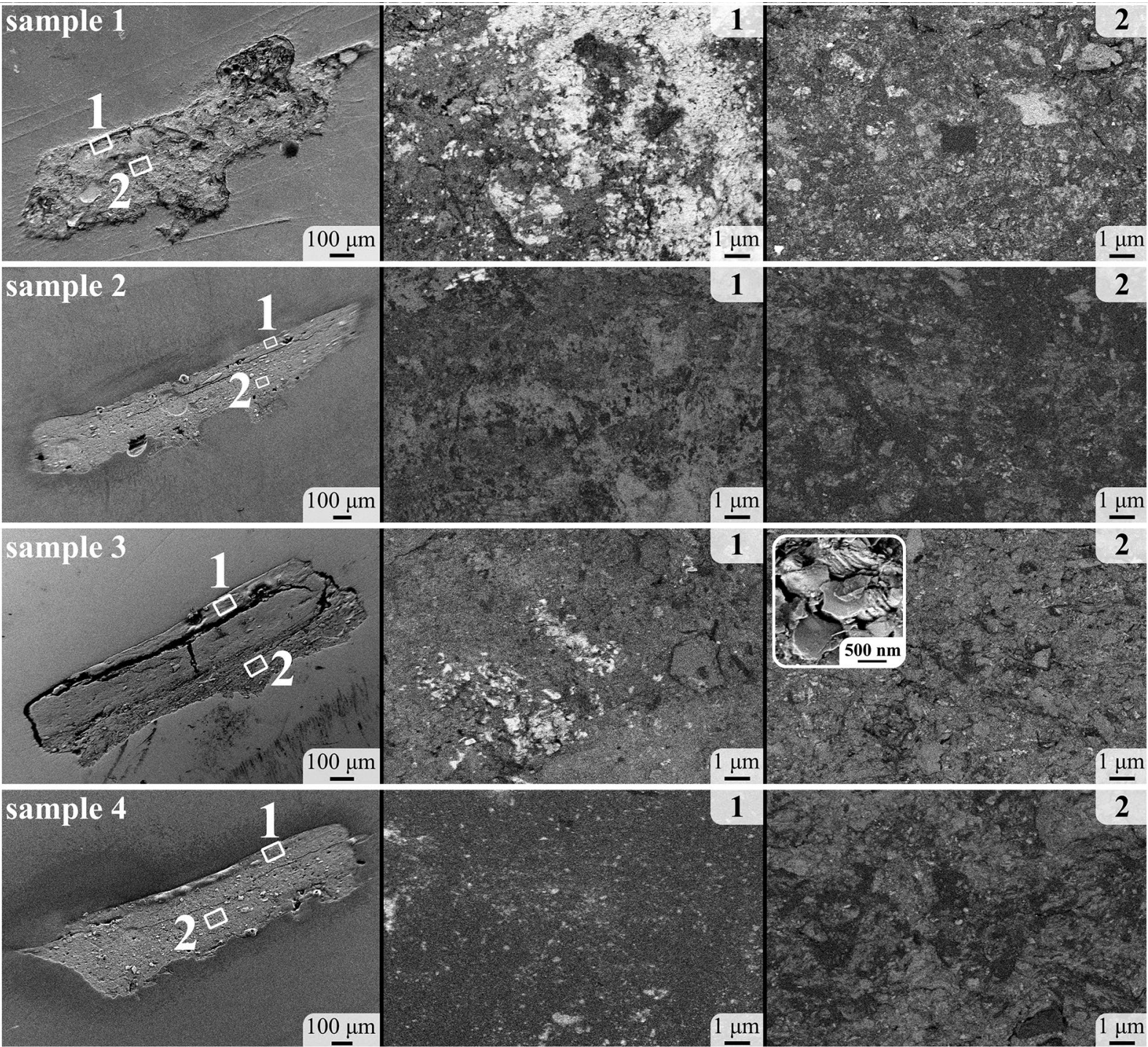

Fig. 4 The appearance of cross-sections of samples 1-4 (left) and the microstructure of the corresponding upper paint layers (central column) and ground (right) in the phase contrast mode (according to SEM) 
and manganese in this case determine the colour of the brown layer. The ground composition of this sample includes lead, iron, titanium, potassium and calcium. It is interesting that these elements, in the same order in terms of content, make up part of the paint layer of sample No. 4. The ground composition of the latter is similar, with the exception of potassium and calcium.

\section{Scanning electron microscopy combined with energy dispersive X-ray spectroscopy}

A comparative analysis of cross-sections of samples 1-4 using the SEM method in phase contrast mode (distribution by the average atomic number) made it possible to evaluate the microstructure of all paint and ground layers, as well as the number and dispersion of their constituent components having different molar masses (Fig. 4).

As can be seen from the micrographs, the paint layers of sample No. 1 contained a significant amount of inorganic components, with a quite large molar mass and an average agglomerate size of about $350 \mathrm{~nm}$, a noticeable proportion of which, with an average size of $450 \mathrm{~nm}$, was also present in the light ground. Therewith, at least four components with different molar masses were observed in the structure of the specified layers. In the dark ground layer of this sample, there were almost no heavy compounds, and its microstructure was similar to the grounds of samples 2 and 4, with quite non-uniformly distributed components with a relatively similar molar mass. The paint layers of sample No. 2 contained at least four types of inorganic components with different molar masses, including a small number of heavy ones that were also present in the ground, but they were more evenly distributed, and had an average size of about $250 \mathrm{~nm}$. In the ground composition of this sample, a much higher content of light components was observed, but in the paint layers they were distributed more locally in the form of agglomerates with a size of about $300 \mathrm{~nm}$. A significant amount of heavy components was observed in the green paint layer of sample No. 3, but there were fewer of them than in the paint layers of sample No. 1. The concentration of inclusions of this type in the ground was close to that of the similar layer of sample No. 2. Therewith, as can be seen from micrographs, in general, the content of light elements in the layers of sample No. 3 was noticeably lower than was the case of sample No. 2. As noted above, the ground microstructure of sample No. 4 was similar to that for sample No. 2, but there were much more components with an average molar mass. The paint layer structure of sample No. 4 was the most homogeneous compared to other samples, and was characterised by the presence of relatively heavy inclusions about $250 \mathrm{~nm}$ in size, but these were lighter than those in samples 1 and 3 . The analysis of the section surface microstructure of the studied samples using a secondary electron detector showed that the dark ground of sample No. 1 and grounds of samples 2, 3, and 4 contained inclusions in the form of separate flakes, which is typical for clays, in particular kaolinite $\left(\mathrm{Al}_{4}\left[\mathrm{Si}_{4} \mathrm{O}_{10}\right](\mathrm{OH})_{8}\right)$.

Then, in order to clarify the chemical composition of the layers of samples 1-4, the EDX method was used to generate maps of the element distribution over the surface of the corresponding sections (Fig. 5), and to perform the elemental analysis (excluding carbon and oxygen) of the paint layers, ground, and locally sited inclusions within them (Table 2). In the case of sample No. 1, it can be seen that the dark ground layer significantly differed in chemical composition from the light layer, where lead was the main element. In addition to lead, the structure of the green layer contained approximately the same amount of silicon and a noticeable content of calcium (7.9\%), aluminium (7.7\%) and iron (6.4\%). The brown layer and the light ground contained a similar set of chemical elements, but the concentration of lead compounds was almost doubled (64.9 and 77.3\%, respectively), and the absence of silicon and the presence of titanium were noted ( 0.8 and $0.2 \%$, respectively). The inclusions present in the green layer mainly contained lead (36.6\%), calcium (29.1\%) and silicon (17.3\%), and in the light ground, the inclusions were almost entirely composed of lead compounds (99.8\%). Thus, it can be assumed that the main component of the green and brown paint layer, as well as the light ground, was white lead. The dark ground of this sample contained mainly silicon (47.3\%), aluminium (19.2\%) and iron (19\%). Consequently, the main component of this layer was probably kaolinite, and almost individual compounds of calcium (99.9\% - probably calcium carbonate), lead (91.4\%white lead) and silicon ( 100\%-quartz) were observed as three types of locally distributed inclusions. Titanium contained in all layers, except for the green one, can be considered an impurity, due to its small amount (0.2$1.4 \%)$, which, in particular, is especially typical for kaolin clays [20].

When analysing the maps of chemical element distribution on the section surface of sample No. 2, there was a clear difference between the ground and the paint layers, which was manifested in an increased amount of silicon $(54.3 \%)$ and aluminium $(24.6 \%)$ compounds. The main components of the green paint layer were silicon (36.5\%), aluminium (17.1\%) and lead (14.9\%). Components of two types were observed as inclusions: probably white lead (lead content about $70 \%$ ) and accumulations of silicon (36\%), aluminium (20.3\%) and lead (19.3\%) compounds. The presence of copper (0.03\%) apparently determines the green pigment content in the studied paint layer: malachite $\left(\mathrm{CuCO}_{3} \cdot \mathrm{Cu}(\mathrm{OH})_{2}\right)$ or verdigris 


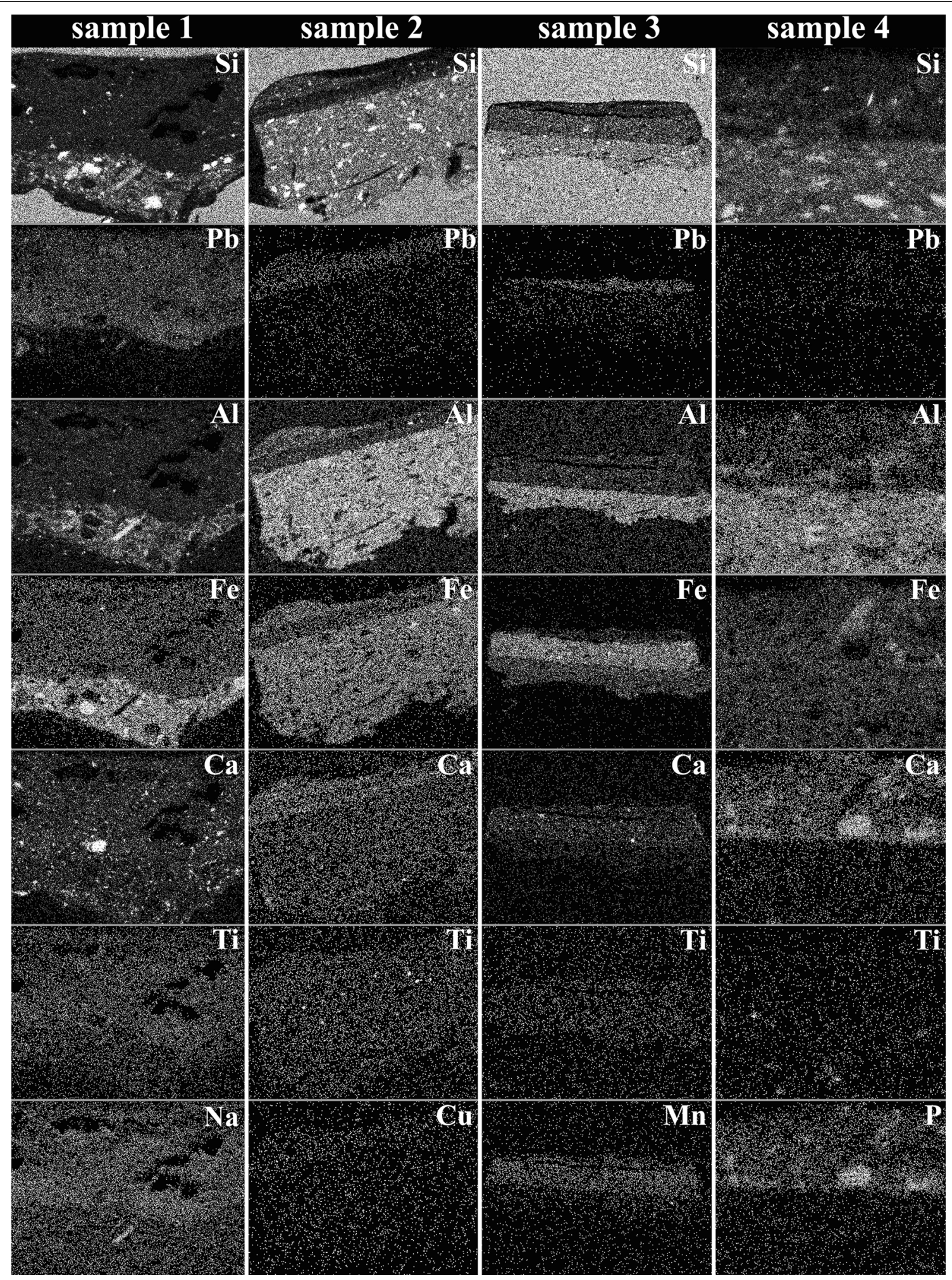

Fig. 5 Maps of the element distribution over the surface of cross-sections of samples 1-4 


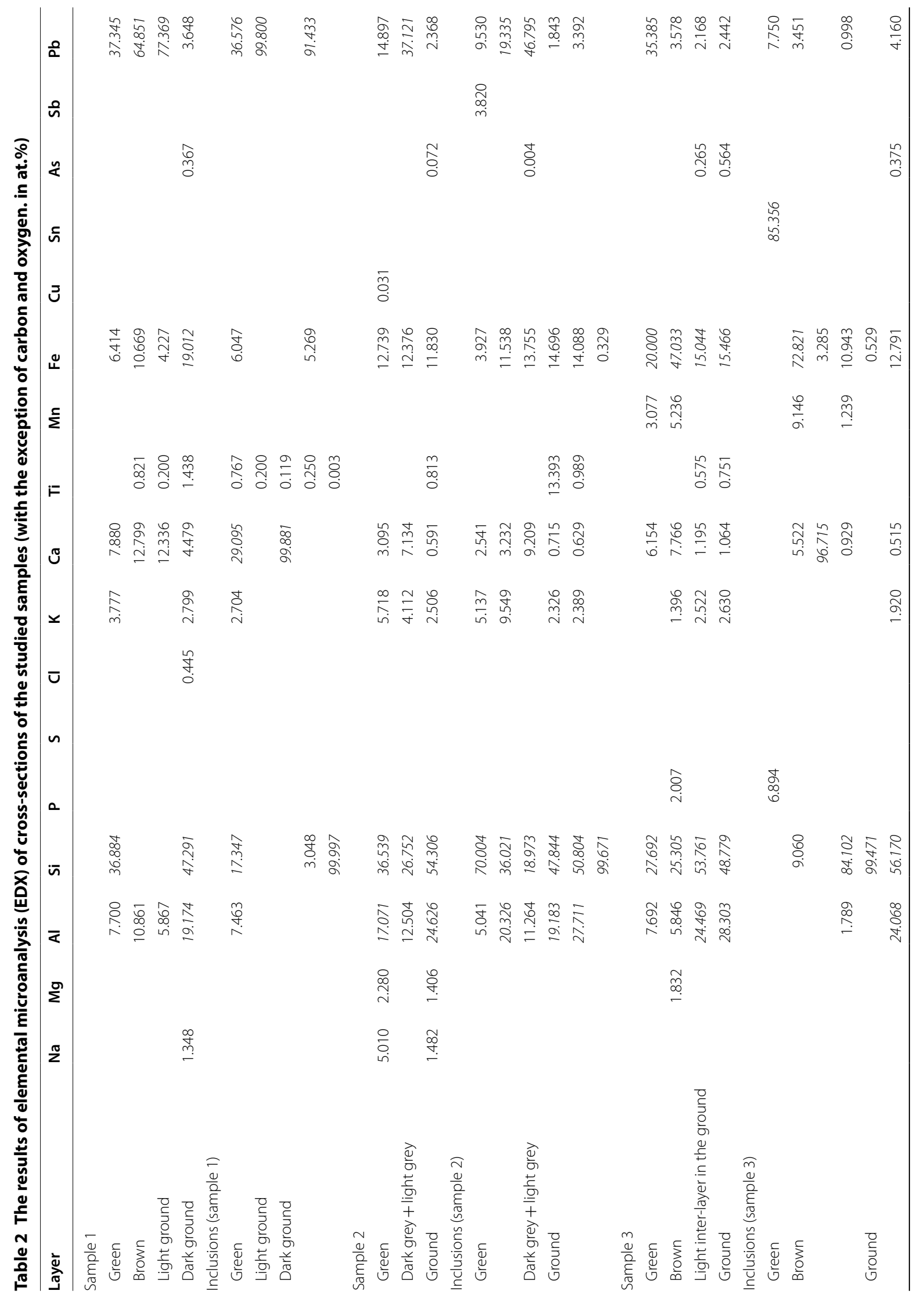




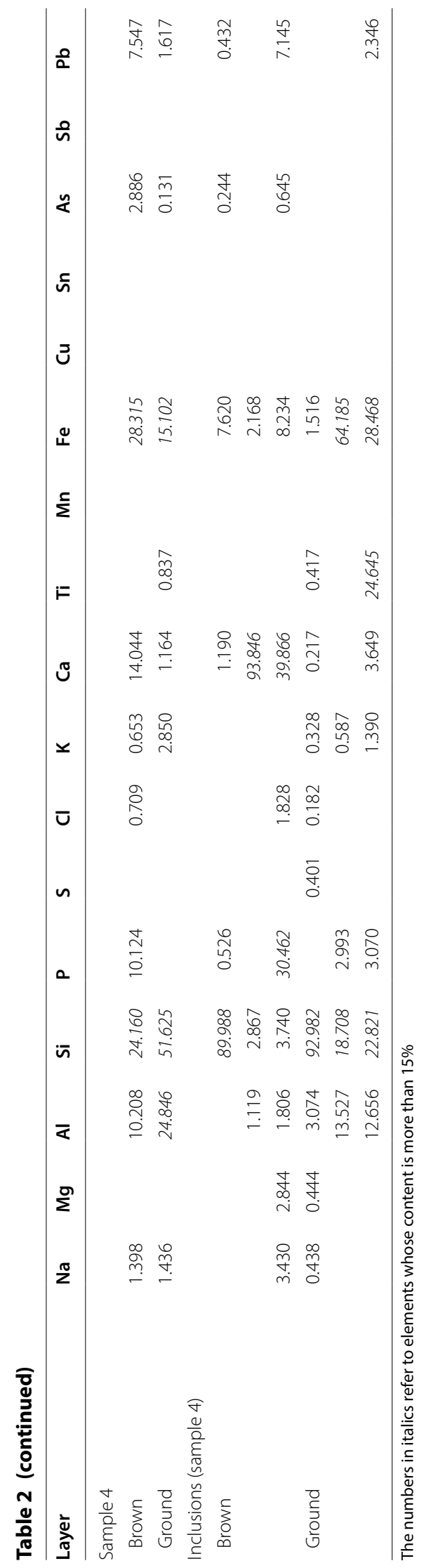


$\left(\mathrm{Cu}\left(\mathrm{CH}_{3} \mathrm{COO}\right)_{2} \cdot 2 \mathrm{Cu}(\mathrm{OH})_{2}\right)$. The thinner dark grey and light grey paint layers below contained mainly lead (37.1\%), silicon (26.8\%), aluminium (12.5\%) and iron (12.4\%), as well as inclusions with an increased (46.8\%) content of lead compounds. The ground of sample No. 2 contained silicon (54.3\%) and aluminium (24.6\%) as the main components, which indicated the use of kaolinite as a filler. The inclusions present in this layer can be attributed to quartz (silicon content-99.7\%) and large fragments of kaolin clay (silicon-48-51\%, aluminium-19-28\%). The mapping results also show that, in the light inter-layer area in the upper part of the ground of this sample, there was a small amount of quite large inclusions containing about $13.4 \%$ of titanium, which is probably an impurity in the composition of kaolinite.

The maps of the element distribution over the section surface of sample No. 3 show noticeable differences in the chemical composition of the three layers. Thus, the green layer contained a high content of lead (35.4\%), the compounds of which in other layers were present in trace amounts (2.2-3.6\%). In addition, the upper paint layer contained a large amount of silicon $(27.7 \%)$ and iron (20\%). The content of tin-based inclusions in this area $(85.4 \%)$ can presumably indicate the presence of a small amount of yellow pigment, which is consistent with the corresponding shade of the underlying area of the painting. As can be seen from the maps and the elemental analysis results, the brown paint layer contained iron compounds (47\%) as the main component and three types of inclusions based on calcium (96.7\%), silicon (84.1\%) and iron (72.8\%). The composition of this layer also included manganese compounds (5.2\%), which is clearly indicated on the corresponding map. Thus, the colour of this layer could have been caused by the use of umber or ochre mixed with calcite and quartz. The ground of sample No. 3 mainly contained silicon (48.8\%), aluminium (28.3\%) and iron (15.5\%), which apparently indicated the use of kaolinite as a filler. In this case, there were two types of inclusions: quartz (silicon content-99.5\%) and large kaolinite fragments (silicon content-56.2\%, aluminium-24.1\%), the increased content of which can explain the tint of the light layer in the upper area of the ground. Titanium $(0.6-0.8 \%)$ observed in the ground composition can be attributed to the impurity that is typical when kaolinite is used as a filler.

Maps of the element distribution over the section surface of sample No. 4 also make it possible to observe a clear boundary between the paint layer and the ground, showing noticeable differences in their chemical composition. The content of the main ground components (Si-51.6\%, Al-24.8\%, Fe-15.1\%) almost completely coincided with the ground of sample No. 3, (including the presence of inclusions of quartz, silicon content-93\%), although they were on different extension pieces and were located quite far from each other on the canvas. In general, according to the main component (kaolinite) content, these grounds were similar to the ground of sample No. 2 and the dark ground of sample No. 1. In this case, using the average content of iron compounds, these grounds can be arranged in the order $2<4<3<1$. Probably due to having the lowest ochre content, the ground of sample No. 2 was the lightest one. It should also be noted that two other types of inclusion (in addition to quartz) were observed in the ground composition of sample No. 4 , consisting of iron $(64.2 \%)$ and silicon (18.7\%), as well as iron (28.5\%), titanium (24.6\%) and silicon (22.8\%). As can be seen from the element distribution maps, rather large titanium-based inclusions, as in the case of the ground of sample No. 3, were quite distinct and might have been an impurity of the main filler-kaolinite. An interesting fact is that the elemental analysis of the paint layer of sample No. 4 showed a similar chemical composition to that of the brown layer of sample No. 3, which, in addition to containing iron (28.3\%) and silicon (24.2\%) as the main components, was also evident due the presence of a detectable amount of phosphorus (10.1\%) and calcium (14\%). In this case, inclusions explicitly found in the paint layer of sample No. 4, consisting of phosphorus (30.5\%) and calcium (39.9\%), indicated the possible use of black bone pigment $\left(\mathrm{Ca}_{3}\left(\mathrm{PO}_{4}\right)_{2}+\mathrm{CaCO}_{3}+\mathrm{C}\right)$. This assumption additionally confirms the presence of calcium-based inclusions (93.9\%) and a rather dark brown shade that cannot be obtained with ochre alone. The presence of quartz inclusions (silicon content-90\%) in the brown paint layer of sample No. 4 , as well as a noticeable similarity of the chemical composition of the grounds, suggests that parts of the painting on the first and second extension pieces, from which samples 3 and 4 were taken, were formed at the same time.

Returning to sample No. 1, it can be seen that the corresponding light ground layer was significantly different in microstructure and chemical composition to the grounds of other samples. The two-layer ground structure in the main part of the painting was also confirmed by optical microscopy, and the use of two-layer grounds, as described above, was typical for works by Levitsky. Thus, the ground structure on the main part of the canvas differed from the single-layer grounds typical of the first and second extension pieces.

\section{micro-FTIR}

Based on the results of elemental analysis of cross-sections of samples 1-4 obtained by XRF and EDX methods, micro-FTIR was used to establish a list of the main classes of inorganic components and to evaluate the type of binder included in all layers (Fig. 6). The analysis 

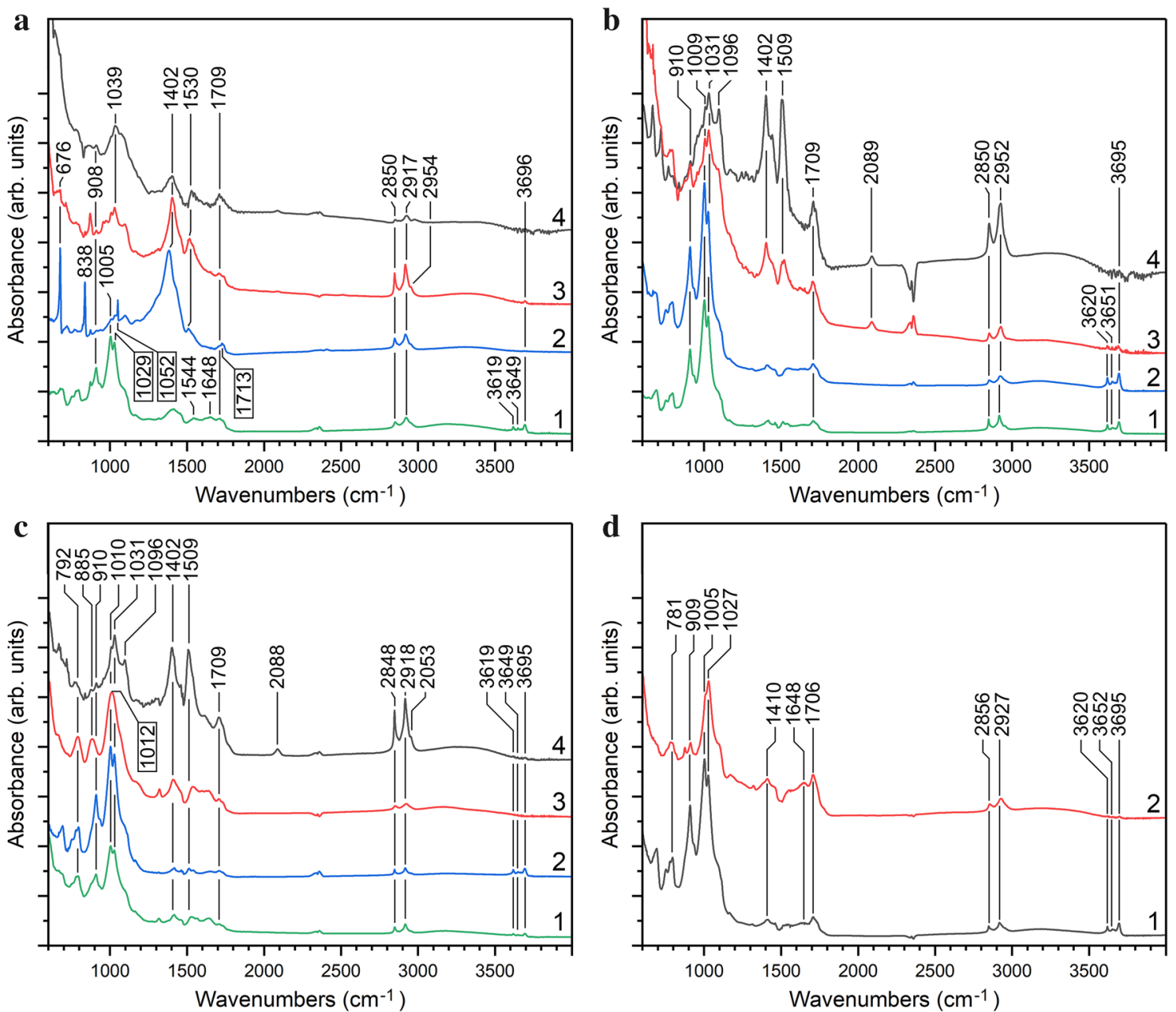

Fig. 6 Characteristic IR spectra of cross-sections of samples: No. 1 a 1—dark ground, 2-light ground, 3-brown, 4-green; No. 2 b 1-ground 2-light inter-layer in the ground, 3-dark grey, 4-green; No. 3 c 1-ground, 2-light inter-layer in the ground, 3-brown, 4-green; No. 4 d 1ground; 2-brown

of the green paint layer spectra of sample No. 1 made it possible to single out kaolinite (a series of absorption bands in the region of $\left.900-1100 \mathrm{~cm}^{-1}\right)$ [21] and malachite $\left(\mathrm{CuCO}_{3} \cdot \mathrm{Cu}(\mathrm{OH})_{2}\right)$ (absorption bands with maxima at 1402 and $1530 \mathrm{~cm}^{-1}$, as well as bands overlapping with the signal from kaolinite in the region of 1000$1100 \mathrm{~cm}^{-1}$ ) as the main types of inorganic components [22]. The presence of malachite is not consistent with the results of elemental analysis of this paint coating, (no copper was detected), but this can be explained by the low concentration of this pigment in the filler made from kaolinite and white lead. Thus, FTIR proved to be a more sensitive method for determining malachite than EDX. In the IR spectrum of the brown layer, the set of absorption bands corresponding to kaolinite (912, 1008 and $1030 \mathrm{~cm}^{-1}$ ) was more pronounced, and the intensity of the band from white lead was much higher than in the case of the green layer. The low-intensity absorption band with a maximum at $2083 \mathrm{~cm}^{-1}$ observed in the spectrum of the green and brown layers probably referred to vibrations of $\mathrm{CN}$ bonds of Prussian blue present in these regions $\left(\mathrm{Fe}_{4}\left[\mathrm{Fe}(\mathrm{CN})_{6}\right]_{3}\right)$ [9], which agreed with the elemental analysis results, (there is a detectable amount of iron). For the light ground, a typical spectrum of white lead was observed with maxima of absorption bands at $676,838,1052$ and $1400 \mathrm{~cm}^{-1}$, and the dark ground, according to the analysis, consisted of almost pure kaolinite, according to the presence of typical absorption bands in the region of $3600-3700 \mathrm{~cm}^{-1}$ related to vibrations of $\mathrm{OH}$ groups [21]. Thus, the last two layers have a fundamentally different chemical composition.

As can be seen from the IR spectra of the ground of sample No. 2 and the light inter-layer in its upper part, these regions mainly consisted of kaolinite, (the spectral 
properties were similar to the dark ground of sample No. 1). For the green and dark grey paint layer, there was an absorption band that was more intense than those of sample No. 1, with a maximum at $2089 \mathrm{~cm}^{-1}$, probably related to the Prussian blue that was present. The presence of absorption bands with maxima at 1402 and $1509 \mathrm{~cm}^{-1}$, as well as in the wave number range of $1000-1100 \mathrm{~cm}^{-1}$, for all three thin paint layers indicates the presence of malachite as a green pigment, as in the case of the green paint layer of sample No. 1. The much higher intensity of the absorption bands, that have been assigned to malachite, observed for the green layer of sample No. 2, probably indicated a higher concentration of this pigment in the filler, (this is also noticeable in the canvas appearance in this area-Fig. 1), which led to the detection of copper $(0.031 \%)$ in the composition of this layer, by EDX. The absorption bands with maxima at
1009 and $1031 \mathrm{~cm}^{-1}$ in the spectra of the two upper paint layers indicate the presence of a rather large amount of kaolinite.

The IR spectra of the ground of sample No. 3 and the light inter-layer in its upper part were similar to the spectra of similar zones of sample No. 2, and indicate the presence of kaolinite as the main component. The set of bands for the green paint layer in this case were also similar to the green layers of samples 1 and 2, indicating the presence of malachite as a green pigment in the matrix of kaolinite. The presence of Prussian blue was confirmed by the appearance of an absorption band with a maximum at $2088 \mathrm{~cm}^{-1}$, and this also makes it possible to point out the similarity of the green paint layers of samples 1,2 and 3. Thus, we can assume that the green paint layers of these samples were formed at the same
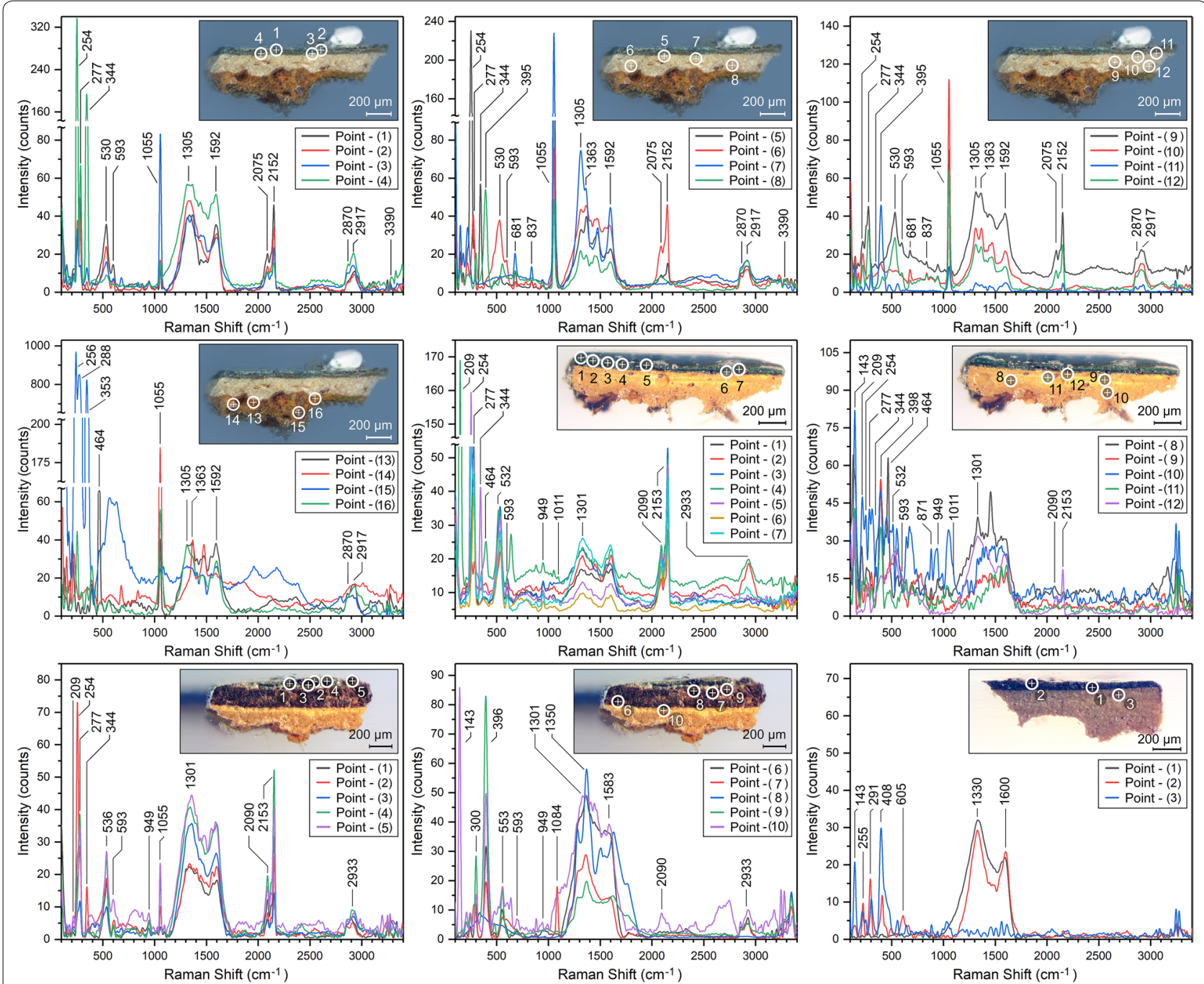

Fig. 7 Characteristic Raman spectra of cross-sections of samples 1 (a), 2 (b), 3 (c) and 4 (d) 
time. For brown paint layers of samples 3 and 4, the set of absorption bands was similar to a mixture of yellow ochre $\left(\mathrm{FeO}(\mathrm{OH}) \cdot \mathrm{nH}_{2} \mathrm{O}\right)$ with kaolinite [23], and the presence of phosphates is possible for them, which are characterised by an intense absorption band maximum position at about $1020 \mathrm{~cm}^{-1}$. The ground of sample No. 4, according to the analysis, mainly consisted of kaolinite. As can be seen, the brown layers of samples 3 and 4 were similar in their spectral characteristics, despite the significant remoteness of their sampling sites from each other and their location on different fragments of the canvas.

According to FTIR, the «old»oil acted as a binder in the paint layers, and this was manifested in the presence of an absorption band at about $1710 \mathrm{~cm}^{-1}$ and the absence of a band at $1740 \mathrm{~cm}^{-1}$ [24].

\section{micro-Raman spectroscopy}

After establishing the main classes of inorganic components contained in the paint layers and grounds of samples 1-4, using the micro-FTIR method, micro-Raman spectroscopy was used to more accurately determine their composition (Fig. 7). Thus, when analysing the green and brown paint layers of sample No. 1, white lead was confirmed by the presence of a mode with a maximum at $1055 \mathrm{~cm}^{-1}$ on the corresponding spectra [11, $12]$, and the bands at 254,277 and $344 \mathrm{~cm}^{-1}$ belonged to vermillion inclusions (HgS) [25]. Prussian blue inclusions $\left(\mathrm{Fe}_{4}\left[\mathrm{Fe}(\mathrm{CN})_{6}\right]_{3}\right)$ were also found in the green paint layer, corresponding to FTIR results. Interpreting the light ground spectra showed the presence of a high content of white lead with vermillion and Prussian blue inclusions. In the spectra at points 8 and 11, located close to the dark ground and the brown paint layer, respectively, absorption bands with a maximum at $395 \mathrm{~cm}^{-1}$ were observed, maybe relating to the presence of yellow ochre inclusions $\left(\mathrm{FeO}(\mathrm{OH}) \cdot \mathrm{nH}_{2} \mathrm{O}\right)$ [25]. Spectral analysis of the dark ground showed the presence of white lead and kaolinite [13], as well as inclusions of vermillion, Prussian blue and yellow ochre.

When analysing the ground of sample No. 2, the presence of kaolinite was detected, and the light inter-layer in its upper part also contained Prussian blue inclusions. All three thin paint layers of this sample were characterised by inclusions of Prussian blue and (with the exception of the dark grey layer) vermillion. The ground of samples 3 and 4 also contained kaolinite, and yellow ochre was also present in the light inter-layer in the upper part of the ground of sample No. 3. The structure of the green paint layer of this sample included white lead, inclusions of Prussian blue and vermillion, as in the case of samples 1 and 2. The brown layer (sample No. 3) contained calcite $\left(\mathrm{CaCO}_{3}\right)$, which manifested itself in the presence of an absorption band at $1084 \mathrm{~cm}^{-1}$, and yellow ochre. The absorption bands on the spectrum of the paint layer of sample No. 4 were rather weak, but the analysis of their set made it possible to detect hematite $\left(\mathrm{Fe}_{2} \mathrm{O}_{3}\right)$ [26].

An analysis of the spectral properties of the varnish flake samples, using micro-FTIR and micro-RS (Fig. 8), made it possible to establish natural resin as the main component, which, in particular, was confirmed by the shift of the absorption band of the $\mathrm{C}=\mathrm{O}$ bond to the region of lower wavenumbers (up to $1706 \mathrm{~cm}^{-1}$ ) in the IR spectra [15].

Thus, as a result of the studies, it was found that there was a two-layer ground in sample No. 1. White lead was found in the upper (white) layer, and kaolinite was the main component in the lower (brown) layer. Samples
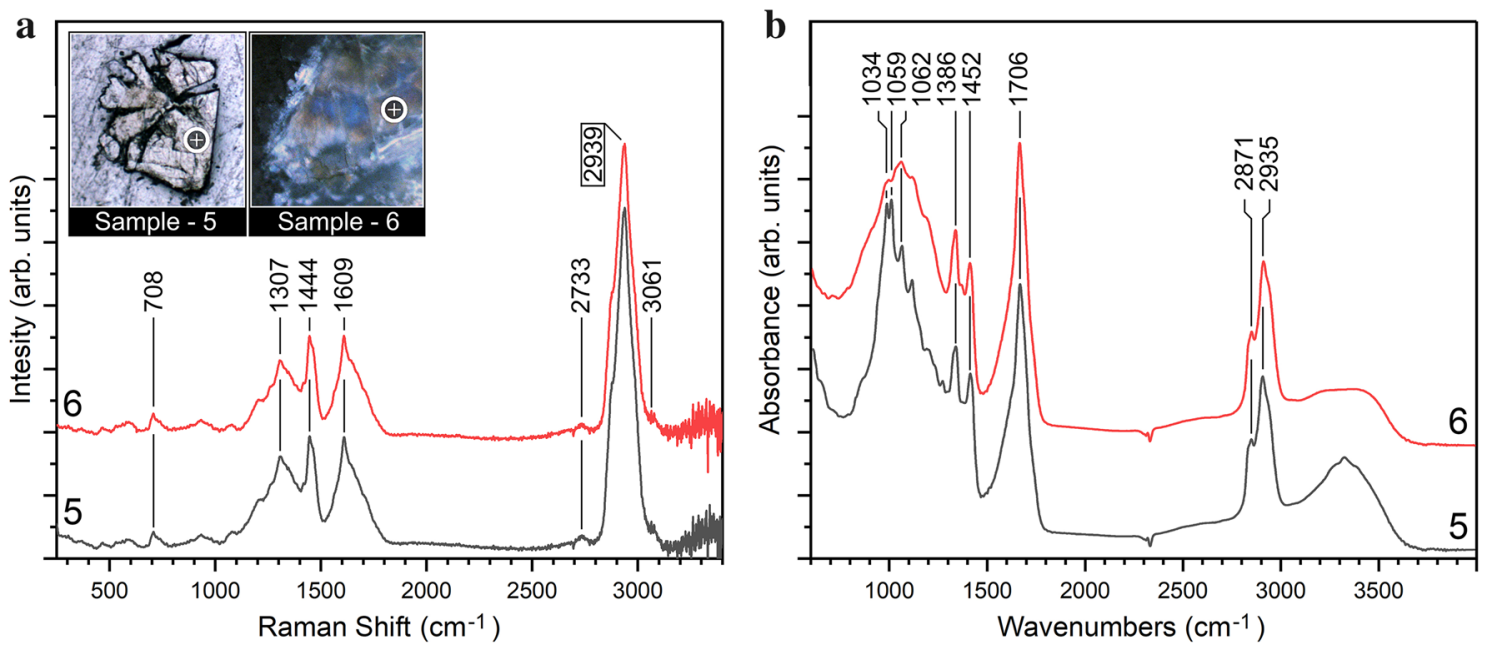

Fig. 8 Raman spectra (left) and IR spectra (right) recorded from the surface of varnish flakes 


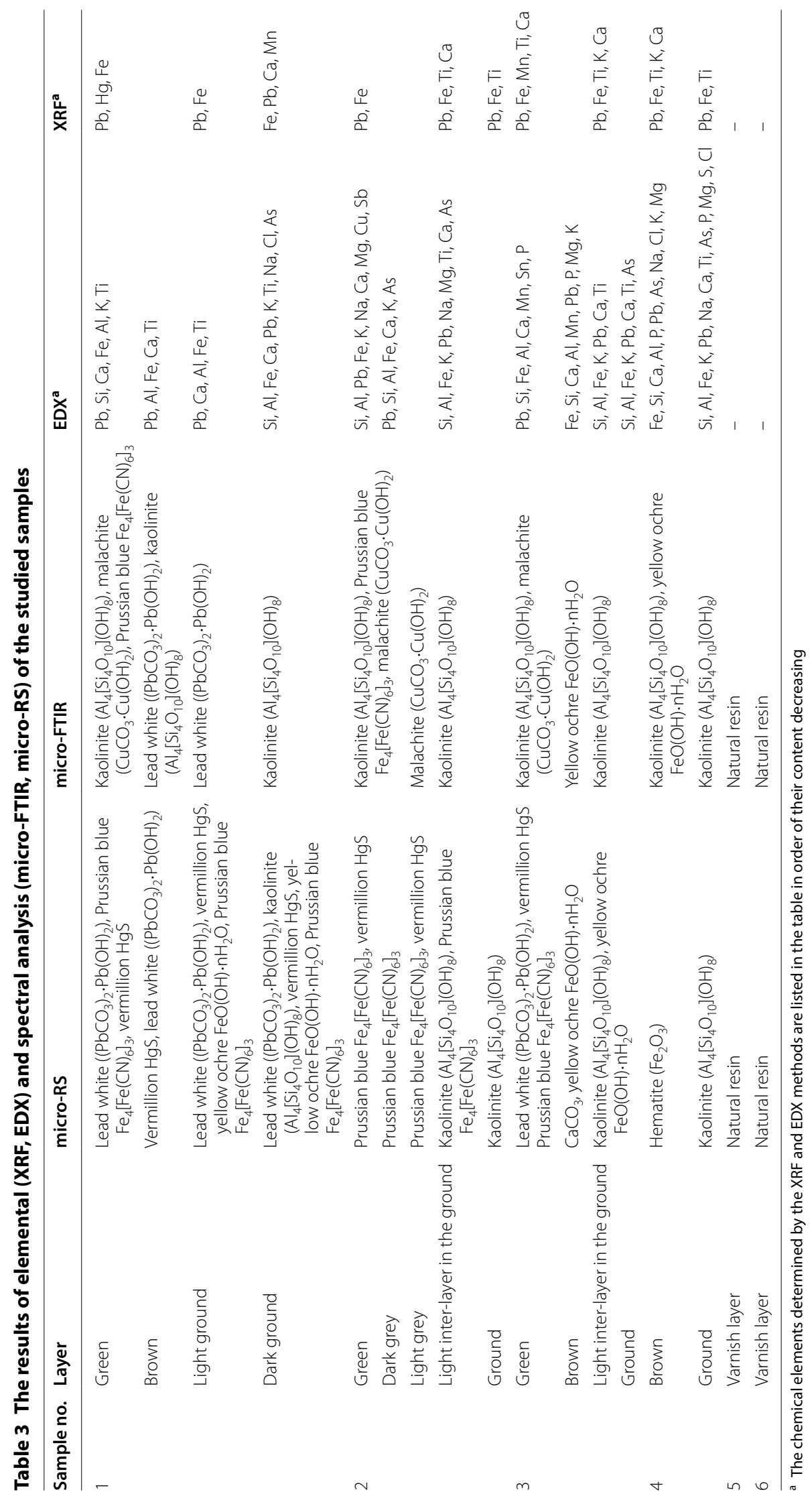


2, 3 and 4 were located at a considerable distance from one another and on different extension pieces of the canvas. They demonstrated presence of a single-layer brown ground, and its main component was kaolinite. As is known from the literature, in the 17-18 centuries, clay was used as a ground component in European painting [27]. At the same time, a similarity of pigments (malachite) and spectral characteristics in the paint layers of samples 1-3 was observed, which is very important in answering the questions posed to conservators.

All this is invaluable evidence to support the hypothesis that a single artistic process united all three parts of the canvas. Originally, the painter prepared a canvas with two layers of ground and a certain size in accordance with the composition conceived. It is likely that the concept had changed during the process, which required bigger canvas size. As such, this process might have taken place in a hurry, as suggested by the following factors. The nature of the grounds of the extension pieces is similar to those of the main part, but simplified in structure. For the required size, two narrow extension pieces were used, rather than one accurately measured. The second piece was sewn with a seam that was much coarser than the first one. It is especially noteworthy that canvas extension pieces were also observed in some other works of the artist.

The data obtained using the specified set of physicochemical analysis methods (Table 3) are complementary and consistent, and can be considered to be a significant contribution to the further conservation of the "The Portrait of F.P. Makerovsky in a Masquerade Costume" by Levitsky.

\section{Conclusions}

A study of rare historical materials has helped us to form a clearer picture of previous conservation interventions in Levitsky's work. In turn, the physico-chemical studies of "The Portrait of F.P. Makerovsky in a Masquerade Costume" has made it possible to clarify the stratigraphy of the author's painting, and to study in more detail and compare the parts of the sewed canvasses (extension pieces). Thus, the results of the study indicate the unity of the paint layers in all three sections of the canvas and the fact that they were formed in close periods. At the same time, it is interesting that in the manufacture of the main part of the canvas, a two-layer ground was used, and in the case of extension pieces, it was single-layer ones. In this paper, the efficiency of the algorithm used was shown, consisting in a set of analysis methods, as well as in the order of their application. It is shown that the spectrum of the analysis methods used is necessary, which, in particular, was demonstrated during the FTIR detection of malachite as a component of the green layers of the samples studied, when other methods were insensitive to it. It should be emphasized that such a detailed study of this painting has been carried out for the first time, which is important for further study of the works of Levitsky. The work reported in this paper has substantial methodological value not only for technological studies of Russian painting works of the late eighteenth-early nineteenth centuries but can also be useful to a broad scientific community when conducting pre-conservation studies of such objects of cultural heritage.

\section{Abbreviations \\ ATR: attenuated total reflection; Micro-FTIR: micro-Fourier-transform infrared spectroscopy; IR spectra: infrared spectra; micro-RS: micro-Raman spectros- copy; LED: light-emitting diode; XRF: X-ray fluorescence spectroscopy; SEM: scanning electron microscopy; EDX: energy-dispersive X-ray spectroscopy.}

\section{Acknowledgements}

The authors would like to express their gratitude to the State Tretyakov Gallery for providing samples and materials for study. SEM measurements were performed using shared experimental facilities supported by IGIC RAS state assignment.

\section{Authors' contributions}

NPS generalised the entirety of the results obtained, wrote the main body of the text and performed SEM-EDX analysis. VRS carried out Raman spectroscopy examination and provided relevant images. KVS performed micro-FTIR analysis and provided images. AAL carried out the SEM-EDX mapping and interpretation of the relevant results. SVL provided interpretation of the Raman spectroscopy results and wrote the section describing the experimental method. EAL performed XRF-spectroscopy examination and provided relevant images. TVS carried out sampling from the painting and contributed to the content of the text. IGB and YAK provided information on the historical background of the painting and supervised the sampling. YuBD interpreted XRF-spectroscopy results and wrote the relevant part of the discussion section. TLS and EPS analysed micro-FTIR data and contributed to the relevant part of this publication. IAV contributed to the discussion of the results and supervised the work of VRS and SVL. VVI is the leader of the project, and provided professional opinions and writing advice for this article. All authors read and approved the final manuscript.

\section{Funding}

This work was supported by the Russian Foundation for Basic Research (Project No 17-29-04349).

\section{Availability of data and materials}

The datasets used and/or analysed during the current study are available from the corresponding author on reasonable request. The datasets supporting the conclusions of this article are included within the article.

\section{Competing interests}

The authors declare that they have no competing interests.

\section{Author details}

${ }^{1}$ Moscow Institute of Physics and Technology, Institutskiy per. 9, Moscow Region, Dolgoprudny 141701, Russia. ${ }^{2}$ Kurnakov Institute of General and Inorganic Chemistry of the Russian Academy of Sciences, Leninsky pr., 31, Moscow 119991, Russia. ${ }^{3}$ State Tretyakov Gallery, Lavrushinsky Lane, 10, Moscow 119017, Russia.

Received: 19 October 2019 Accepted: 17 January 2020

Published online: 27 January 2020 


\section{References}

1. Manuscript Research Department of State Tretyakov Gallery. Section F. 230. ed.xp.22 (in Russian)

2. Van Der Snickt G, De Nolf W, Vekemans B, Janssens K. $\mu$-XRF/ $\mu-R S$ vs. SR $\mu$-XRD for pigment identification in illuminated manuscripts. Appl Phys A Mater Sci Process. 2008;92:59-68.

3. Schmidt BA, Ziemann MA, Pentzien S, Gabsch T, Koch W, Krüger J. Technical analysis of a Central Asian wall painting detached from a Buddhist cave temple on the northern Silk Road. Stud Conserv. 2016:61:113-22.

4. van Loon A, Noble P, Krekeler A, Snickt G, Janssens K, Abe Y, et al. Artificial orpiment, a new pigment in Rembrandt's palette. Herit Sci. 2017:5:26.

5. Castro K, Knuutinen U, Vallejuelo SFO, Maguregui M, Madariaga JM, Laakso R. Spectroscopic analysis used to uncover the original paint colour of the Helsinki Government Palace tower clock faces. Herit Sci. 2016:4:36.

6. Adami G, Gorassini A, Prenesti E, Crosera M, Baracchini E, Giacomello A. Micro-XRF and FT-IR/ATR analyses of an optically degraded ancient document of the Trieste (Italy) cadastral system (1893): a novel and surprising iron gall ink protective action. Microchem J. 2016;124:96-103. https://doi. org/10.1016/j.microc.2015.07.020.

7. Bikiaris D, Daniilia S, Sotiropoulou S, Katsimbiri O, Pavlidou E, Moutsatsou AP, et al. Ochre-differentiation through micro-Raman and microFTIR spectroscopies: application on wall paintings at Meteora and Mount Athos, Greece. Spectrochim Acta Part A Mol Biomol Spectrosc 2000:56:3-18.

8. Centeno S, Guzman M, Yamazaki-Kleps A, Della Vedova C. Characterization by FTIR of the Effect of Lead White on Some Properties of Proteinaceous Binding Media. J Am Inst Conserv. 2004:43:139-50.

9. Rajendran S, Rathish RJ, Prabha SS, Anandan A. Green Electrochemistry - a versatile tool in green synthesis: an overview. Port Electrochim Acta. 2016;34:321-42. http://www.peacta.org/articles_upload/ PEA $34 \quad 52016$ 321 342.pdf.

10. Caggiani MC, Cosentino A, Mangone A. Pigments Checker version 3.0 a handy set for conservation scientists: a free online Raman spectra database. Microchem J. 2016;129:123-32. https://doi.org/10.1016/j.micro c.2016.06.020.

11. Burgio L, Clark RJH, Firth S. Raman spectroscopy as a means for the identification of plattnerite $\left(\mathrm{PbO}_{2}\right)$, of lead pigments and of their degradation products. Analyst. 2001;126:222-7.

12. Hibberts S, Edwards HGM, Abdel-Ghani M, Vandenabeele P. Raman spectroscopic analysis of a "noli me tangere" painting. Philos Trans R Soc A Math Phys Eng Sci. 2016;374:20160044.

13. Murad E. Identification of minor amounts of anatase in kaolins by Raman spectroscopy. Am Mineral. 1997:82:203-6.

14. Vandenabeele P, Ortega-Avilès M, Castilleros DT, Moens L. Raman spectroscopic analysis of Mexican natural artists' materials. Spectrochim Acta Part A Mol Biomol Spectrosc. 2007;68:1085-8
15. Daher C Paris C, Le Hô AS, Bellot-Gurlet L, Échard JP. A joint use of Raman and infrared spectroscopies for the identification of natural organic media used in ancient varnishes. J Raman Spectrosc. 2010:41:1494-9.

16. Rybnikov AA. The texture of the classic painting. Moscow; 1927 (in Russian).

17. Luzhetskaya AN. Oil painting technique of Russian masters from the 18th to the beginning of the 20th century. Moscow; 1965 (in Russian)

18. Zabelin scientific readings. Moscow; 1998 (in Russian).

19. Catalog of the State Tretyakov Gallery. Section L. D.G. Levitsky. 1987. (in Russian).

20. Savko AD, Novikov VM, Krainov AV, Davydov DN, Ratnikov VYu. Minerageny of Atsk sediments of the Voronezh anteclise. Bull Vor State Univ Ser Geol. 2011;116-36. (in Russian)

21. Mgbemena CO, Ibekwe NO, Sukumar R, Menon ARR. Characterization of kaolin intercalates of oleochemicals derived from rubber seed (Hevea brasiliensis) and tea seed (Camelia sinensis) oils. J King Saud Univ Sci. 2013;25:149-55. https://doi.org/10.1016/j.jksus.2012.11.004.

22. Buti D, Rosi F, Brunetti BG, Miliani C. In-situ identification of copper-based green pigments on paintings and manuscripts by reflection FTIR. Anal Bioanal Chem. 2013:405:2699-711.

23. Institute of Chemistry University of Tartu E. Database of ATR-FT-IR spectra of various materials. Yellow ochre. 2015. http://lisa.chem.ut.ee/IR_spectra/ paint/pigments/yellow-ochre/.

24. van der Weerd J, van Loon A, Boon JJ. FTIR studies of the effects of pigments on the aging of oil. Stud Conserv. 2005;50:3-22.

25. Dominguez-Vidal A, De La Jose Torre-Lopez M, Rubio-Domene R, AyoraCañada MJ. In situ noninvasive Raman microspectroscopic investigation of polychrome plasterworks in the Alhambra. Analyst. 2012;137:5763-9.

26. Marić-Stojanović M, Bajuk-Bogdanović D, Uskoković-Marković S, Holclajtner-Antunović I. Spectroscopic analysis of XIV century wall paintings from Patriarchate of Peć Monastery, Serbia. Spectrochim Acta Part A Mol Biomol Spectrosc. 2018;191:469-77.

27. Hradil D, Hradilová J, Bezdička P, Švarcová S. Differentiation between anonymous paintings of the 17 th and the early 18 th century by composition of clay-based grounds. Appl Clay Sci. 2015;118:8-20. https://linki nghub.elsevier.com/retrieve/pii/S0169131715301022.

\section{Publisher's Note}

Springer Nature remains neutral with regard to jurisdictional claims in published maps and institutional affiliations.

\section{Submit your manuscript to a SpringerOpen ${ }^{\circ}$ journal and benefit from:}

- Convenient online submission

- Rigorous peer review

- Open access: articles freely available online

- High visibility within the field

Retaining the copyright to your article

Submit your next manuscript at springeropen.com 